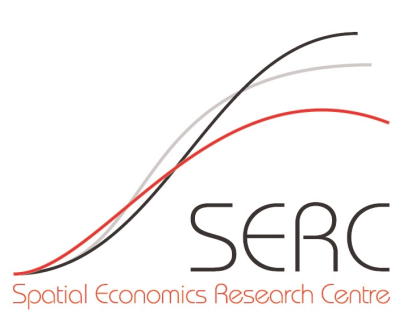

SERC DISCUSSION PAPER 3

\title{
Re-Investment and the Survival of Foreign-Owned Plants
}

Colin Wren (SERC, Newcastle University Business School) Jonathan Jones (Newcastle University Business School)

August 2008 
This work was part of the research programme of the independent UK Spatial Economics Research Centre funded by the Economic and Social Research Council (ESRC), Department for Business, Enterprise and Regulatory Reform (BERR), the Department for Communities and Local Government (CLG), and the Welsh Assembly Government. The support of the funders is acknowledged. The views expressed are those of the authors and do not represent the views of the funders.

(C) Colin Wren and Jonathan Jones, submitted 2008 


\title{
Re-Investment and the Survival of Foreign-Owned Plants
}

\author{
Colin Wren* and Jonathan Jones**
}

August 2008

* Economics, Newcastle University Business School

** Newcastle University Business School

Acknowledgements

Earlier versions of this paper were presented at the Britain and Irish section of the Regional Science Association, the European Regional Science Association, Centre for Public Policy for Regions at Glasgow University and a staff seminar at Cardiff Business School. We acknowledge the comments received from participants at these events, and from Peter Dolton, Richard Harris, Bud Weinstein and John Wildman. Funding under the UK ESRC Spatial Economics Research Centre is gratefully acknowledged, and so is the support of the Regional Development Agency One NorthEast and numerous individuals at regional and national levels who helped with the dataset. 


\section{Abstract}

Foreign-owned plants have higher conditional exit rates, but this paper tests the hypothesis that re-investment "embeds" these plants, leading to significantly longer survival time durations. A unique dataset is used for 265 plants that commenced in foreign ownership after 1985 in North East England, distinguishing between start-up ("greenfield”) and acquisition plants. Survival is measured at 2000, and the paper analyses the duration to the first reinvestment and survival, allowing for selection into the multiple investment state. It finds that re-investment increases the lifetime of start-up plants, but this is insignificant once selection is controlled for, while for acquisition plants there is no difference. Grants affect selection, but not the survival of start-up plants. The paper offers little support for re-investment as a source of "embeddedness".

JEL classification: O12, L20, R58

Keywords: FDI; re-investment; plant survival; exit; duration analysis; grants 


\section{Introduction}

The promotion of foreign direct investment (FDI) is an important economic development objective of governments and agencies throughout the industrialised world (Friedman, 1992; Kim et al, 2003; and Crozet et al, 2004). However, success in attracting the plants is blighted by their failure, with exit hazard rates for multinational and foreign-owned plants up to 40 per cent higher than for domestic plants with similar characteristics (Görg and Strobl, 2003; Fabbri et al, 2002; and Colombo and Delamstro, 2000). ${ }^{1}$ Further, failure rates increase with plant size (Harris and Hassaszadeh, 2002), while there is evidence that a foreign-based takeover reduces a plant's lifetime (Girma and Görg, 2003). This poses a dilemma for the policymaker, as FDI tends to locate in the high unemployment areas, especially in manufacturing (Coughlin et al, 1991), in part attracted by the inducements that are designed to stimulate the older industrial regions (Head et al, 1999; Gabe and Kraybill, 2002; and Jones and Wren, 2008a). ${ }^{2}$

The issue of plant closure has long-held the interest of regional economists and those concerned with regional development (see Fothergill and Guy, 1990), but the response of the policymakers is to seek to "embed" foreign-owned plants in the regional economy in order to forestall exit. "Embeddedness" is defined in terms of the networks and relationships that exist between the investor and local institutions, and it has received considerable attention in the regional and international business literatures (e.g. Belderos et al, 2001; and Andersson et al, 2002). It is given operational meaning in a recent study by Phelps et al (2003), who identify the plant-level characteristics associated with "embeddedness". These are the plant's function and position in the corporate hierarchy; level of research and development; skills demand; its reliance on local supply chains; and its investment behaviour, specifically re-investment, i.e., 
repeat investment. Some of these aspects are explored elsewhere, e.g., Görg and Strobl (2002) on supply linkages and Criscuolo and Salter (2006) on innovation, but here the relationship between survival and re-investment is investigated, i.e. repeat investment.

Repeat investment is little examined in the literature, and in this paper the effect of reinvestment on the survival time duration is explored for foreign-owned plants. Of course, key issues are that the decision to re-invest is likely to be endogenous, while there may be factors that are unobservable that may affect both survival and re-investment, potentially biasing the estimates that are obtained. The topic that is addressed therefore is whether foreign-owned plants survive for longer once these endogeneity effects are controlled for. If they do, it can be argued that re-investment is qualitatively different to initial investment, i.e., it "embeds" plants, with implications for development. Thus, the paper's focus is on an important policy concern, so that while no claims are made to novelty in theory, the results and methodology that are brought to bear have direct policy relevance, as well as being of academic interest.

The study is carried out for the North East of England, using a unique dataset on FDI projects that has been constructed for the period 1985-2000. This region has offered grants for investment under UK regional policy, and relative to its size it has attracted more FDI than any other English region, although it has also experienced a considerable attrition of its FDI stock (Jones and Wren, 2006). The dataset identifies re-investments, enabling a very good match to be made with the grant data, which is used to help determine selection. The approach is to use time duration analysis to fit parametric distributions to the plant's survival behaviour that allow for non-monotonic behaviour in the underlying hazard rate (McCloughlin and Stone, 1998). A distinction is made by entry mode, according to "greenfield" start-ups and acquisition plants. Overall, the paper finds little evidence for the "embeddedness" effect of repeat investment, as while new foreign-owned plants that re-invest survive for about an extra 7 to 8 years compared to similar plants, it takes about this long to carry out the first re-investment. 
The paper is organized as follows. Section 2 motivates the analysis, and describes the dataset and nature of FDI in the study area. Section 3 outlines the estimation approach, and Section 4 sets out the variables. Re-investment is investigated in Section 5 and the relationship with survival is examined in Section 6. Conclusions are drawn in Section 7.

\section{Motivation for the Study}

Ultimately, the issue of whether re-investment "embeds" foreign-owned plants is an empirical matter, but it can be motivated in several ways. First, a re-investment may "capital deepen" by adding functions that are associated with the other features of "embeddedness" outlined above, e.g. research capacity. In this way, it may form part of a firm's investment strategy to build-up capacity in a region over time, increasing plant survival. Second, re-investment may "capital widen" by adding scale, and thereby make a plant more able to withstand shocks in its input and output markets. For example, Watts and Kirkham (1999) find that the increased sunk cost of re-investment makes it less vulnerable to closure by its parent company in adverse economic conditions. Finally, re-investment may be associated with the classic motives for FDI (Culem, 1988), all of which have implications for plant survival. For strategic reasons a re-investment

may forestall entry by other firms in the host economy, it may enable a firm to put in place its specific technology or it may benefit from a "learning-by-doing" effect in foreign markets.

Each of these provides a sound reason for the "embeddedness" of repeat investment, but contrary to this re-investment could just signal the greater strength of the plant itself, which is a selection effect. These are the intrinsic strengths of the plant (better capital, management, industry and so on), and which manifest themselves in a greater commitment of a company to sustain the plant after entry (Young et al, 1994). In this case, re-investing plants survive for 
longer compared to other plants, but a re-investment project has no effect on survival different from an initial investment, as it merely signals the greater strength of the plant.

\subsection{The Dataset}

The North East of England provides a good test bed in which to examine the survival effect of re-investment by foreign-owned plants. It is relatively underdeveloped, but since the 1980 s and before it has offered grants to encourage FDI location, much of it in manufacturing, although subsequently up to half of these plants have closed (Jones and Wren, 2008b).

The data used in this study were supplied by the Regional Development Agency for the North East of England, which along with its predecessors has collected investment data on foreign-owned plants in the region since 1985. The data are now collected for all UK regions, and are the primary source by which FDI is reported for the country as a whole by the main inward investment agency, UK Trade and Investment. A feature of the data is that they report projects, which include the investments by which the plant commenced in foreign ownership start-up, acquisition, merger or joint venture - as well as re-investment. The latter are in situ projects that involve an enhancement of the plant's operating capacity, e.g. new production line or other substantial upgrading, but do not include the routine replacement or other trivial forms of investment. They are the kinds of re-investment that are of interest to this study.

The data are believed to provide to a comprehensive account of FDI in the region over the study period, and better than that available from elsewhere. The collection of FDI data is well developed in the English regions, and forms part of a framework by which the UK reports FDI for the country as a whole. In the case of North-East England the agencies have had a major inward investment function since the early 1980s, maintaining overseas offices and upto-date files on all known foreign-owned plants in the region (there were 500 plants in 2000). 
They collate information from national, regional and local bodies, making regular contact with investors as part of a development programme, and undertaking periodic surveys.

The data have an advantage over the census data, which is important for identifying the first re-investment. This is because the UK production "census", the Annual Business Inquiry, samples only a proportion of smaller companies, which for some years can be as little as 1 in 5 for firms with less than 100 employees (see Griffith, 1999). However, in the study area threequarters of foreign-owned plants have less than 100 employees at start-up. Potential omissions of data on re-investments cannot be known, but the extent to which this is an issue it seems more likely to occur in the less well-known smaller plants (which would certainly be the case if the census data were used), so that as a robustness check we later disaggregate the results by plant size. ${ }^{3}$ Nevertheless, in the extensive checking of the data nothing came to light to make us question its reliability, and we believe it gives a comprehensive account of foreign-owned investment in a UK region, so that it is therefore representative

As a further point, the paper's focus on projects treats investment as intermittent and lumpy, but this is consistent with the literature that analyses investment episodes (e.g., Cooper et al, 1999). These other studies tend to use census data, but even here there is an element of subjectivity as an investment episode is defined if the investment rate exceeds some multiple of the median rate, e.g. in Nilsen and Schiantarelli (2003) it is 2.5. An episode differentiates large investments from frequent periods of zero or small investment, and so it is comparable to the re-investment projects that are considered in this study.

\subsection{Definition of a Plant and Exit}

Details were supplied on 416 investment projects over 1985-98. ${ }^{4}$ These were put on a plant basis, which is defined as a production unit at which the same activity is carried out more or less continuously over time in the region. ${ }^{5}$ The definition reflects the paper's interest in the use 
to which the assets provided by an investor are being used for development purposes, so that a unit is treated as the same plant even though it may later have changed its name, ownership or location in the region, e.g., a unit that anglicizes its name after start-up or is later taken over is regarded as the same plant. It is a consistent method of assigning projects to plants, and while ambiguities are inevitable (Haltiwanger and Schuh, 1999) these are of no practical significance.

This definition of a plant frames the definition of an exit, as a production unit that is no longer defined as the same plant at the year 2000 is treated as a non-survivor. This is like Dunne et al (1988), except that a plant relocating outside the region (and possibly overseas) is treated as an exit as it is no longer contributing to the regional economy. In fact, the FDI plants are located towards the "centre" of the region, so that few plants, if any, relocate short distances to locations outside the region. Another difference is that a plant is regarded as on-going even if it is taken over by another firm, provided the assets continue in the same use, whereas Dunne et al regard it as an exit, reflecting their interest in market structure.

The 416 projects were carried out by 265 plants, and Table 1 gives details of the plants, disaggregated by the plant type, where this defined by the entry mode of the initial investment

over 1985-98, for which standard definitions apply. ${ }^{6}$ All plants existed in the region at some time over this period, and nothing came to light to make us think that the re-investment projects did not go ahead. ${ }^{7}$ Table 1 shows there are 164 start-ups, 79 acquisitions and 22 joint-ventures. The start-up plants are sometimes referred to as "greenfield" investments, while the acquisition projects include a small number of mergers. On average, the plants carried out 1.57 projects, which is little different across types. The other characteristics are discussed below.

\subsection{Investment in the Study Area}

The UK is a foremost recipient of FDI, and relative to its size the North East has received more FDI than any other English region (by both number of projects and scale), although similar to 
Scotland and Wales. Most of the FDI is in manufacturing, which is like the other peripheral British regions in receipt of regional policy (Brand et al, 2000), although unlike the core region of South-East England. The total number of FDI projects and associated jobs in the region relative to the rest of the UK is shown in Table 2. This picks out the increase in FDI, and later decrease, which is apparent for all regions outside the South East region.

The North-East has been a long-term recipient of UK regional policy, and the Regional Selective Assistance (RSA) grant scheme ran throughout the period, representing the primary financial instrument by which the UK has attracted FDI to its regions (Devereux et al, 2007; Jones and Wren, 2008a). For the UK as a whole, FDI accounts for about ten per cent of RSA cases, but about half of the regional assistance budget (Wren, 2005). The grant is discretionary and made towards investment in plant, machinery or buildings for job-related projects in the designated Assisted Areas, with much of the populated part of the region designated for grants. An excellent match was made between the RSA grant and FDI project data, which was helped by both datasets being held for projects on an historical basis. It compares very favourably with similar exercises elsewhere. ${ }^{8}$ In total, the 265 plants in the dataset were offered about $£ 250$ million (\$500 million) in RSA grant on which a payment was made (1995 prices). Table 1 shows that 92 of the 265 plants received a grant at some time over $1985-98$, of which $28 \%$ received more than one award, and there is little difference across types. Start-up projects were offered a mean grant of $£ 2.4 \mathrm{~m}$ compared to $£ 1.9 \mathrm{~m}$ for joint ventures, $£ 1.5 \mathrm{~m}$ for acquisitions and $£ 1.2 \mathrm{~m}$ for re-investment projects. The re-investment projects were more likely to receive a grant (41\%) compared to start-up projects $(30 \%)$.

The analysis is conducted at the plant level, and two kinds of plant are of interest: Multiple Investors, which carry out at least one subsequent investment after entry up to 1998; and Single Investors, which are not observed to re-invest. Table 1 shows that $98(37 \%)$ of the 265 plants are Multiple Investors, and that this is little difference across types. Of these, $62 \%$ 
carried out one re-investment by $1998,24 \%$ carried out two further projects and $14 \%$ carried out more than this (not shown). The other 167 (63\%) plants are Single Investors, which form the comparison group for our study. This is advantageous as not only are they foreign-owned (similar UK plants will have lower exit rates, according to the discussion in the Introduction, although we have no data for these), but the data were collected over the same period and on the same basis. The Single Investors may have implemented projects after 1998, which is a form of data censoring, while it may be that they were not observed to re-invest as they either entered towards the end of the study period or because they exited. These issues are taken-up below. Table 1 shows that 50 plants exited by 2000, which is higher for the start-ups.

\section{Empirical Approach}

At the outset, it is useful to briefly outline of the nature of duration data at our disposal. For each plant commencing after 1985 and re-investing we observe the year of the transition to the status of a Multiple Investor, unless of course there is right censoring at the end of the period in 1998, in which case or otherwise it is a Single Investor plant. Further, the year in which a plant commenced in foreign ownership is known, but the survival status is known only at 2000. This is a further form of censoring, as the year in which a surviving plant exited after 2000 is not observed, although neither is the year in which a non-surviving plant exited prior to this time. This kind of data is encountered in other studies of survival, such as Cressy (1996), and it is handled in the estimation by the specification of the log-likelihood function. This enables both kinds of censoring to be modelled, from which the exit hazard rates can be unscrambled.

Formally, let $t$ denote time in years, where investment is observed over the time interval $\left[t_{0}, t_{1}\right]$ and survival is observed at time $t_{2}$, where $t_{2}>t_{1}$ (i.e., $t_{0}=1985, t_{1}=1998$ and $t_{2}=2000$ ). Further, let $S\left(\Delta t_{i} \mid \boldsymbol{x}_{i}\right)$ be the conditional survivor function, where $\Delta t_{i}$ is the observed duration 
between the initial investment and $t_{2}$ and $\boldsymbol{x}_{\boldsymbol{i}}$ is a vector of covariates. Then, if a plant $i$ survives to time $t_{2}, S\left(\Delta t_{i} \mid \boldsymbol{x}_{\boldsymbol{i}}\right)$ is observed, whereas if the plant does not survive, $1-S\left(\Delta t_{i} \mid \boldsymbol{x}_{\boldsymbol{i}}\right)$ is observed. Letting $\delta_{i}$ denote an indicator variable for these states, the log-likelihood function is:

$$
\log L=\sum_{i}\left[\delta_{i} \log \left\{1-S\left(\Delta t_{i} \mid x_{i}\right)\right\}+\left(1-\delta_{i}\right) \log S\left(\Delta t_{i} \mid x_{i}\right)\right]
$$

Equation (1) is maximized for each of the log-logistic, Weibull and the lognormal distributions for $S\left(\Delta t_{i} \mid \boldsymbol{x}_{\boldsymbol{i}}\right)$, of which the log-logistic is preferred (see below). Once $S\left(\Delta t_{i} \mid \boldsymbol{x}_{\boldsymbol{i}}\right)$ is determined, so is the hazard $h\left(\Delta t_{i} \mid \boldsymbol{x}_{i}\right)$, which has identical parameterization. The hazard is the probability of exit after an interval $\Delta t_{i}$ given that the plant survived up to this time. The log-logistic survivor and hazard functions have the following form (see Greene, 2003, p. 941):

$$
S\left(\Delta t_{i}\right)=\frac{1}{1+\left(\mu \Delta t_{i}\right)^{\kappa}}, \quad h\left(\Delta t_{i}\right)=\frac{\mu \kappa\left(\mu \Delta t_{i}\right)^{\kappa-1}}{1+\left(\mu \Delta t_{i}\right)^{\kappa}},
$$

where $\kappa$ is the shape parameter. When $\kappa>1$, there is an increasing and then decreasing hazard rate as the duration increases, but when $\kappa \leq 1$ there is a monotonic decreasing hazard rate. They are parameterized by setting $\mu \equiv \exp \left(-x_{i} \beta\right)$. The results are interpreted by examining the median survival duration, i.e. $S\left(\Delta t_{i} \mid \boldsymbol{x}_{i}\right)=1 / 2$, which gives $\Delta t_{i}=\exp \left(\boldsymbol{x}_{\boldsymbol{i}} \beta\right)$. Given the estimates below this is about 1.33 times the duration at which the hazard rate is at aximum. ${ }^{9}$

To examine whether re-investing plants survive for significantly longer durations, the plant's status either as a Multiple or Single Investor, MULTIPLE, is added as a covariate. The decision to re-invest is likely to be non-random between plants, so that this term is endogenous and it is treated as a selection issue. It leads to a two-stage estimation procedure that is due to Lee (1976) and given in Maddala (1983). Details of this are set out in Appendix 1, but broadly 
it involves estimating a probit for selection into the status of Multiple Investor, and then from this forming selection terms, $\lambda_{i m}$ and $\lambda_{i s}$, for the Multiple and Single Investors respectively, which are then included as additional covariates in the estimation of (1). This has aspects of the classic omitted variable problem, with $\lambda_{i m}$ and $\lambda_{i s}$ representing the omitted variables. Of course, with the inclusion of these terms the interest is in whether MULTIPLE is significant of not, and hence whether re-investment leads to significantly longer survival durations.

There are several points about the broad approach. First of all, our interest is less in the estimates of the covariates, which other than MULTIPLE are essentially conditioning variables, than in the structure of the durations, and this is why parametric methods are used. Second, the selection terms are formed on the assumption of a jointly normal error distribution between the probit and the regression for survival in (1) with (2a). In fact, the latter has an unknown error structure, while normality is the usual assumption in this context, but subsequently we estimate proportional hazards survivor functions under normal errors, and here the assumption of jointly normal errors has more validity (see Appendix 1).

Third, the probit is run with data for different durations, but other things equal plants that are observed for shorter time periods may be less likely to re-invest, while if they are also less likely to exit then they have greater opportunity to re-invest. To tackle this, the probit model is estimated with fixed effects for the time duration over which each plant is observed. These are omitted when forming the selection terms. Finally, the probit supposes that the plant characteristics associated with selection are time invariant, but more importantly that selection is made on observables only. This is problematic as if there are unobserved factors that affect both survival and re-investment then it may bias the estimate of MULTIPLE. The approach is to run the above model with survival data, but then to jointly estimate equations for survival and re-investment under a proportional hazards model to test for unobserved effects. 


\section{4. $\quad$ The Variables}

The variables are given in Appendix 2, while further descriptive statistics are in Table 3 below, disaggregated by the Multiple and Single Investors. Part (a) of Appendix 2 shows that the data give details of plant, industry and regional characteristics, many of which are categorical, but grouped into a small number in order to improve meaning (zero values give the base case). The variables are generally measured at the time of the initial investment and for 265 plants. However, there are a small number of cases where the plant size could not be ascertained, and this means that there is a reduced sample of 242 plants when these terms are included in the survival analysis, of which 147 are start-ups and 75 are acquisitions. Overall, the plants with missing employment data have almost identical survival and re-investment behaviors. ${ }^{10}$

The attention now turns to motivating the variables, although many cannot be signed $a$ priori. This is because more favorable conditions for investment may lead to a larger project size on entry, but reduce the need for re-investment. Likewise, the mode of entry may have an ambiguous effect on re-investment and survival. Thus, an acquisition that puts in place specific technology may be more likely to re-invest and survive than a start-up, but the conversely if the acquisition is for technology sourcing (see Criscuolo et al, 2002).

The plant size and age are important factors in survival (Dunne and Hughes, 1994; Mata et al, 1995), and these may affect re-investment. The plant size is measured by the number of jobs in the initial investment, which in the case of start-ups is the planned jobs within 2 years. Jones and Wren (2004) find a monotonic relationship with the number of jobs later achieved. Age is measured as the difference in years between the establishment of the unit and the time when it commenced in foreign ownership, so that it is zero for a start-up. Since increased size may increase a plant's capacity to raise funds and re-invest but reduce its need to do so, this is 
included in the re-investment equation in a non-linear form. Table 3 below shows that the mean employment size is 168 jobs but the median size is only about 50 jobs.

Other plant-level variables include the plant's location between the metropolitan urban and other areas; whether there are other plants in the region with the same owner; if plants are co-located at the same site, possibly related; and whether the plant later relocated within the region. Each of these may have a bearing on a plant's ability to re-invest and survive. The grant term is included in binary form according to whether the plant received an award in its initial investment. Given that plants receive multiple grants over time (Table 1), this it may be a good determinant of selection into re-investment, and we exploit this below, although it has an uncertain effect on survival. The new economic geography suggests agglomeration effects may dominate, but several studies suggest that grants may have an important early-stage effect on FDI location (e.g., Head et al, 1995; and Jones and Wren, 2008a).

As regards agglomeration, it is known that FDI plants concentrate by activity, which is true of the US (Coughlin and Segev, 2000; and Kim et al, 2003), the UK (Brand et al, 2000) and elsewhere (Guimaraes et al, 2000). It is also true of the study area, where two-thirds of the FDI plants are engaged in manufacturing, half of which are in just four 2-digit activities. ${ }^{11}$ To allow for the fortunes of these industries dummy variables are included for these four activities, and a further term is included for all activities outside manufacturing. As we see, the industries have sharply differing re-investment and survival patterns. Variables are also included at the 2digit level for the minimum efficient scale, market concentration (Herfindahl index) and for the net industry annualized growth rate. These are measured in the same way as Görg and Strobl (2003), with the first two calculated from a dataset on 11,500 FDI projects for Britain over a similar period. Each of these may promote survival, but the effect on re-investment may again be ambiguous. Plants in high-growth industries with larger minimum efficient scales may be more likely to re-invest, but may enter at a larger scale, reducing the need to re-invest. 
Finally, other terms capture events in the host and source economies, which may affect re-investment and survival. These include the growth rate of the regional economy for the year of the initial investment and the sterling exchange rate relative to the plant's source country. In the face of market imperfections, Froot and Stein (1991) find that FDI varies with the exchange rate, such that an appreciation in sterling may make re-investment cheaper in the UK, but make repatriated profits more expensive, adversely affecting survival. The annualized exchange rate for 2 and 5 years after the date of the initial investment were used, of which the latter is better performing. Finally, FDI from different source regions exhibits different investment behavior (Friedman et al, 1992), possibly due to economic or cultural reasons. Dummies are included for whether the initial investment is from North America (mainly US), Western Europe (mainly the near Continent and Scandinavia) or the Far East (mainly Japan). There are a similar number of plants from each of these (see Table 3 below), with only 3 per cent from elsewhere.

With these variables we control for a range of factors affecting plant re-investment and survival. While we would have liked other terms, such as the proximity of competing firms or export status, we have at our disposal a large set of relevant variables. In terms of the duration analysis it is necessary to define temporal variables, which are shown in part (b) of Appendix 2. These are the year of the initial investment, $Y E A R_{I}$, and in the case of the Multiple Investors $(M U L T I P L E=1)$ the year of the first re-investment, $Y E A R_{R}$, and re-investment time duration, $D U R_{R} \equiv Y E A R_{R}-Y E A R_{I}$. We define a variable for whether a plant survived, SURVIVE, and for the time period to the year 2000 , i.e. $D U R_{2000} \equiv 2000-Y E A R_{I}$.

\section{Re-Investment}

The characteristics of the Multiple and Single Investor plants are explored in Table 3. Overall, it shows that a Multiple Investor plant is more likely to be a start-up, to be in manufacturing, in 
receipt of a grant, larger in size and to originate from the Far East. However, it is less likely to locate in an urban area or originate from North America. This provides useful information, but it is unsatisfactory for several reasons. First, the characteristics in Table 3 are correlated, so US FDI is more likely to be through acquisition, tends to be larger, in an urban area and so on. Second, the differences between the Multiple and Single Investors may reflect data censoring. Plants that initially invest later in time are less likely to be observed to re-invest by 1998, and this might explain why the Multiple Investors are observed to undertake their initial investment earlier in time (Table 3). Finally, a surviving plant has more opportunity to re-invest and this could explain why a Multiple Investor is more likely to survive in Table 3. In relation to the first point this is best handled by a multivariate analysis, while the other points are best handled through either the duration analysis or the probit model, as outlined above.

We now consider plant re-investment, which proceeds in stages and addresses the above points. It begins by calculating the re-investment hazard rates using the raw data. This picks up some interesting differences in the re-investment behavior of the different kinds of plant. The formal duration and probit analyses for re-investment are then considered.

\subsection{Empirical Hazard Rates}

For any given duration the re-investment hazard rate gives the probability that a plant becomes a Multiple Investor given that it has not already done so, i.e., it re-invests for the first time. Censoring is less of an issue, as the hazard rates are evaluated for different observed durations, e.g. for the 5-year duration it is the periods, 1985-90, 1986-91, .., 1993-98. Hazard rates are calculated for surviving plants $(S U R V I V E=1)$, although it makes no qualitative difference to the results as the proportion of surviving plants that are Multiple Investors is similar to all plants ( $40 \%$ and $37 \%$ respectively). This means we have a maximum of 191 observations on durations, of which 113 are start-ups and 61 are for acquisitions. 
The empirical hazard rates are evaluated in Table 4. It shows that the hazard rate for a start-up plant is between $7 \%$ and $10 \%$ per annum up to seven years after the initial investment, but much lower for durations of eight years or more. In fact, there are only four plants with an observed duration to the first re-investment of eight years or more. It suggests the "greenfield" investors carry out their first re-investment within seven years or not at all. For the acquisition plants, the first re-investment is sooner, but generally zero after five years. These firms either put their specific technology in place soon after acquisition or not at all.

\subsection{Re-investment Duration}

The re-investment duration is determined by maximising a log-likelihood function of the form (see McCloughan and Stone, 1998):

$$
\log L=\sum_{i}\left[\delta_{i} \log h\left(\Delta t_{i} \mid x_{i}\right)+\log S\left(\Delta t_{i} \mid x_{i}\right)\right]
$$

where $h(\Delta t \mid \boldsymbol{x})$ and $S(\Delta t \mid \boldsymbol{x})$ are the conditional re-investment hazard and survivor functions, $\delta$ $\equiv M U L T I P L E, \Delta t \equiv D U R_{R}$ for a Multiple Investor and $\Delta t \equiv D U R_{2000}$ for a Single Investor (see Appendix 2), $i$ denotes the plant and $\boldsymbol{x}$ are the plant characteristics as before. ${ }^{12}$ The time origin is the year of the initial investment, $Y E A R_{I}$.

Equation (3) is estimated for the Weibull and lognormal hazard functions, but these are nested in the generalized gamma model, and are rejected at $1 \%$ and $5 \%$ levels respectively (see Lawless, 1982, p.26). In fact, the Weibull suggests positive duration dependence in the hazard rate (the probability of re-investment increases the longer is the observed period), but this is confounded by the empirical hazard rates shown in Table $4 .{ }^{13}$ Further, the lognormal imposes negative duration dependence, but this is rejected by the log-logistic function in favor of an increasing and then decreasing hazard rate. Like Cooper et al (1999), it suggests an episode of 
investment exhibits positive duration dependence, although unlike this other study it becomes less likely after a period of time. This is plausible and it is supported by the empirical hazard rates in Table 4. The log-logistic function is also preferred under the Akaike criterion.

The results for the re-investment duration are presented in Appendix 3. It shows that few of the covariates are significant, which suggests that (for plants that re-invest) the time duration to the first re-investment varies little across plants. The significance of the three origin terms arises because plants from the Rest of the World are all Single Investors (Table 3), which means it cannot be entered separately as a covariate. The multi-plant start-ups re-invest sooner, while acquisitions in urban areas, in transport, in services, in concentrated activities or arriving in less buoyant economic times have longer durations. Different functional forms were tried for the plant size, but a quadratic was preferred, which gives a turning point in its effect for all plants of about 450 jobs. In fact, most plants are smaller than this, so that in practice the reinvestment duration decreases at a decreasing rate as the plant size increases.

The median re-investment durations are evaluated in Table 5 for different sizes of plant, based on a re-estimation of the equations in Appendix 3, which includes only a constant term, employment and the three origin terms (which are not significantly different from one another and are restricted to be the same). For start-ups the turning point occurs at about 500 jobs, so that the re-investment duration decreases from 11 years for small plants on entry to a minimum of about 3 years. For acquisitions the turning point is 350 jobs, and for any given size these have longer re-investment durations. It suggests the higher re-investment hazard rates found for these plants over short durations in Table 4 arises from their larger size. Finally, excluding the size terms the re-investment duration for start-ups is about 9 years. This concurs with Table 4, as using the product-limit method (Lawless, 1982) this table suggests a median re-investment duration of about 8 years, although many do not re-invest after this time. 


\subsection{Probit Results}

To obtain the selection terms in (A4) of Appendix 1 it is necessary to regress the probit model in (A3) for the re-investment probability. These results differ from those of the re-investment duration, as while a plant may be more likely to re-invest, it may do so no sooner or later than other plants. Nevertheless, the duration nature of the data is relevant to the probit model for the reasons outlined above, and it suggests the inclusion of fixed effects the duration over which a plant is observed, i.e., 1998 - YEARI. The approach is to include all of the regressors in part (a) of Appendix 2, and to pare these down to their parsimonious forms. These are measured at the time of the initial investment, and include the grant term and a range of characteristics that may be related to a plant's propensity to re-invest, e.g. location, activity and country of origin.

The probit results in Table 6 find support from the simple cross-tabulation for Multiple and Single Investors in Table 3. For the start-ups the grant and other terms are significant at or close to the 1 percent significance level, but for the acquisition plants only the location term is significant. Around two-thirds of the acquired plants are in the urban area, and this seems to condition their ability to re-invest, perhaps because they have an older product, operate in an older industry or are unable to expand due to physical constraints. It is unrelated to the plant's age, which is insignificant when it is also entered in the probit regression.

\section{Plant Survival and "Embeddedness"}

To examine survival equation (1) is maximized by putting $\delta \equiv S U R V I V E, \Delta t \equiv D U R_{2000}$ and the time origin equal to the year of the initial investment, YEAR . The plant characteristics $\boldsymbol{x}$ are those in part (a) of Appendix 2, including MULTIPLE for the Multiple Investor status. Each of the Weibull, log-logistic and lognormal distributions for $S\left(\Delta t_{i} \mid \boldsymbol{x}_{\boldsymbol{i}}\right)$ were tried, but the Weibull gave implausible results (a shape parameter greater than 2 implying a hazard rate that increases 
at an increasing rate with the observed duration), while the negative duration dependence of the lognormal was rejected by the log-logistic in favor of an increasing and then decreasing hazard rate. As such, the log-logistic survivor function in (2a) is preferred.

The survival results are reported in Table 7 for all plants, start-ups and the acquisitions, both with and without selection terms, $\hat{\lambda}_{m}$ and $\hat{\lambda}_{s}$. The selection terms are calculated according to (A4) in Appendix 1 using estimates from the respective probit estimations reported in Table 6 , but omitting the fixed effects. Identification of the selection terms is usually presumed to arise from their non-linear form, but to ensure this the regressors in Table 6 are excluded from the respective equations in Table 7. In fact, the findings are not affected by this, as in all cases the terms fail to achieve significance at the five per cent level in the survival equation, whether the selection terms are included or not. The only exception to this (but at the ten per cent level) is the urban term in the acquisition equation, but this is the only regressor in Table 6 and it may just pick-up this selection effect. Thus, we believe the terms are identified.

Many of the coefficients are significant in at least one of the equations in Table 7, and generally there is little difference in the estimates whether the selection terms are included or not. According to our above discussion, these can be rationalised ex post, so that in the case of all plants they are more likely to survive if there are other plants at the same site, in an industry that is concentrated with a large minimum efficient scale or if the regional economy is growing at the time of the initial investment. An appreciation of sterling is more likely to make a plant close. The initial plant size has a negative effect on the survival of start-ups, which is like that found by McCloughan and Stone (1998) in a study of foreign-owned plants in the region over 1970-93. It reflects the "footloose" nature of the larger FDI plants, while it is reasonable that smaller FDI plants are of a better quality than small plants in general.

Other aspects of the survival results concur with that found elsewhere. Thus, Audretsch and Mahmood (1994) and Stone et al (2008) both find an increasing and decreasing hazard rate 
as the duration increases in the case of new plants. Further, stripping out the covariates in the start-up equation in Table 7 and re-estimating gives a median survival duration of 14.2 years. This is like McCloughan and Stone (1998), who find a peak hazard rate of 12 years.

Of interest is the grant term. A third of the plants receive a grant, and a quarter of these go on to re-invest, such that a Multiple Investor is twice as likely to be assisted compared to a Single Investor. Previously, it was found that grant-aided start-up plants are significantly more likely to re-invest, but they do so no sooner than other re-investing plants, while Table 7 shows that the grant has no effect on their survival. It makes no allowance for their selection as grant recipients, and it may be they are weaker plants (Harris and Robinson, 2005), but it suggests that the performance of the grants is not strong. In fact, the only effect we can find is for the acquisition plants, where the survival duration is doubled (i.e. exp $0.664=1.94$ ) if they receive a grant (Table 7). Otherwise, the principal role of the grants may be to encourage location.

\subsection{Effect of Re-investment on Plant Survival}

The issue of interest is whether re-investment leads to longer survival durations, "embedding" the foreign-owned plants. This amounts to inspecting the coefficient on the MULTIPLE term. Overall, and without controlling for selection, Table 7 shows that all re-investing plants survive for longer compared to the plants that do not re-invest, and that this is related to the start-ups. However, once the selection terms are included, MULTIPLE is insignificant for all plants and for the start-ups (z-values of 1.32 and 1.23 respectively). ${ }^{14}$ In the case of the latter it tells us that once we allow for the characteristics of the plants that multiply invest, then re-investing plants do not survive for significantly longer compared to those plants that do not re-invest.

In the case of the acquisitions the coefficient on MULTIPLE is always insignificant (zvalues of 0.35 and 0.98 for with and without selection terms respectively), which suggests that these plants do not have significantly longer survival durations even when no account is taken 
of selection. In this case, re-investment is not even a signal of a plant's future lifetime. Like McCloughan and Stone (1998), the results in Table 7 reveal that older acquisition plants at the time of acquisition survive for longer, but it has no effect on their re-investment behavior.

Overall, these findings suggest that re-investment does not "embed" the foreign-owned plants, leading to significantly longer survival durations. However, before concluding, it is first useful to check the robustness of this result to some of its assumptions.

\subsection{Unobserved Effects}

The correction for endogeneity based on selection uses observables only. However, there may be factors that affect survival and the re-investment decision, but which are not observed in the data. This will bias upwards the estimate of MULTIPLE, although given the likely direction of this bias and the insignificance of MULTIPLE once selection terms are included it suggests that it is not problematic. ${ }^{15}$ Nevertheless, to address the issue, an approach similar to Lillard (1993) is adopted, in which equations for survival and re-investment are jointly estimated, allowing for correlation in the error terms to capture any unobserved heterogeneity. There are difficulties in applying this directly to (1) as there is censoring and (2a) has an unknown error structure, so like Lillard (1993) and the subsequent literature, it is based on a semi-parametric approach, i.e. proportional hazards. The approach is set out in Appendix 1. Given the joint normality of the errors assumed in the correction for selection this may work very well.

The results (which are not separately reported but available from the authors on request) indicate the presence of unobserved effects. A Breusch-Pagan LM test for a diagonal variancecovariance matrix in the errors between survival and re-investment equations is rejected $\left(\chi^{2}=\right.$ 61.7), while the estimate of the correlation coefficient is high at 0.51 (i.e. $\rho$ in Appendix 1). Of interest is that with the inclusion of the selection terms the estimate on MULTIPLE continues to be strongly insignificant (a z-value of 0.26), suggesting a lack of "embeddedness". 


\subsection{Other Robustness Checks}

Several other checks were made, but none of these overturned the central result. First of all, the Single Investors are the plants from which the selection terms are formed, and while this has certain advantages, it also poses a potential difficulty. This is because the exit transitions are not observed, so that a Single Investor that commences towards the end of the study period may not re-invest because it has not had time, whereas towards the beginning of the study period it may be because it has closed. Of course, this should be controlled for by the time fixed effects in the probit regressions, but as a check the equations for all plants in Table 7 were re-estimated for plants commencing over 1985-91 and 1992-98, which divides the sample roughly equally. However, the same pattern was found for both periods, with MULTIPLE significant at the five per cent level, but insignificant at the ten per cent level when the selection terms are included.

Second, it is useful to calculate the median time survival durations. Since the estimates derived directly from Table 7 are for a baseline plant and may not be representative, these are obtained by re-estimating (1) without covariates (including selection terms). For the start-ups it gives an estimate on MULTIPLE of 0.508 (z-value, 3.58), indicating a median survival duration for a Multiple Investor that is 1.66 times that of a Single Investor (exp $0.508=1.66)$. It implies median survival durations of 19.1 and 11.5 years respectively (a ratio of 1.66), and 14.2 years overall. This is a difference of 7 to 8 years, which compares with a re-investment duration for a median-sized start-up plant of about 9 years (Table 5). Thus, while a Multiple Investor survives for an extra 7 to 8 years it takes about this long to re-invest for the first time, suggesting that a re-investment project is not qualitatively different to an initial investment. ${ }^{16}$

Third, it was suggested that if there are missing observations on re-investment projects then this is likely to be an issue for the smaller plants. Again, the sample was divided into two, but between those start-up plants promising more or less than 50 jobs in the initial investment. 
It was found that smaller plants take longer to implement their first re-investment (Table 5) but that they also survive for longer (Table 7), such that the central result was unchanged.

Finally, the regression constrains the pattern of durations to be the same for Multiple and Single Investors, i.e. $\kappa$ in the survivor function in (2a). To address this, non-parametric and semi-parametric methods are used, but neither contradicted the central result. In the first case, a Wilcoxon test finds a significant difference in the empirical survivor function between the Multiple and Single Investors when the time origin of the former is the date of the initial investment $\left(\chi^{2}(1)=21.04\right)$, but no difference $\left(\chi^{2}(1)=1.22\right)$ when it is the first re-investment. For the semi-parametric case, a Cox proportional hazards model was employed, but stratified to allow the baseline survivor function to vary between the Multiple and Single Investors. A Chisquare test showed no statistical difference in the baseline function between these two kinds of plant $\left(\chi^{2}(13)=2.30\right)$. Thus, the parametric form does not seem to generate the result.

\section{Conclusions}

Relative to comparable domestic plants, foreign-owned plants have higher exit rates, and this paper explores whether re-investment (repeat investment) serves to "embed" these plants in the regional economy, leading significantly longer survival time durations. It utilises a dataset that has been constructed by the authors on 265 plants commencing in foreign ownership in North East of England since the mid-1980s, making comparison between those plants that re-invest and those that do not. Allowing for selection into re-investment and for censoring in both the survival and re-investment data, it finds that start-up plants that re-invest survive for about an extra 7 to 8 years at the median, but there is no such effect once selection is controlled for on observables and for unobserved effects. This is because the start-up plants take about this long to carry out their first re-investment. It suggests that a re-investment is qualitatively the same 
as an initial investment, so that policymakers should not give undue weight to these projects in an attempt to "embed" the foreign-owned plants in the regional economy. 
Table 1: Plant and Project Characteristics

\begin{tabular}{lcccc}
\hline & All plants & Start-ups & Acquisitions & $\begin{array}{c}\text { Joint } \\
\text { ventures }\end{array}$ \\
\hline Number of plants & 265 & 164 & 79 & 22 \\
$\begin{array}{l}\text { Number of projects } \\
\text { (Initial investments) }\end{array}$ & 416 & 260 & 121 & 35 \\
$\quad(265)$ & $(164)$ & $(79)$ & $(22)$ \\
Pre-investments) & $(151)$ & $(96)$ & $(42)$ & $(13)$ \\
Projects per plant & 1.57 & 1.59 & 1.53 & 1.59 \\
No. of regional grants & $92(35 \%)$ & $59(36 \%)$ & $25(32 \%)$ & $8(36 \%)$ \\
$\quad$ Multiple awards & $28 \%$ & $27 \%$ & $28 \%$ & $38 \%$ \\
No. of Multiple Investors & $98(37 \%)$ & $64(39 \%)$ & $26(33 \%)$ & $8(36 \%)$ \\
No. of non-survivors & $50(19 \%)$ & $35(21 \%)$ & $12(15 \%)$ & $3(14 \%)$ \\
\hline
\end{tabular}

Note: Multiple awards are plants that received more than one grant over 1985-98. Multiple Investors carry out at least one re-investment project. Non-survivors exited by year 2000 . 
Table 2: Geographical Distribution of UK Inward FDI: Selected Years

$$
1985
$$

1989

1995

1999

Number of projects:

$\begin{array}{lcccccccc}\text { North-East region } & 26 & (7 \%) & 46 & (14 \%) & 62 & (12 \%) & 25 & (4 \%) \\ \text { Rest of England } & 225 & (60 \%) & 189 & (58 \%) & 286 & (58 \%) & 593 & (78 \%) \\ \text { Rest of UK } & 124 & (33 \%) & 92 & (28 \%) & 148 & (30 \%) & 139 & (18 \%) \\ \text { UK total } & 375 & (100 \%) & 327 & (100 \%) & 496 & (100 \%) & 757 & (100 \%)\end{array}$

Number of associated jobs:

$\begin{array}{lllllllll}\text { North-East region } & 1,987 & (8 \%) & 4,495 & (15 \%) & 6,075 & (14 \%) & 3,399 & (7 \%)\end{array}$

Source: UK Trade and Investment, London.

Note: Figures in parentheses are UK shares. Rest of UK is Scotland, Wales and Northern Ireland. 
Table 3: Characteristics of the Multiple and Single Investors

\begin{tabular}{|c|c|c|c|c|}
\hline & & $\begin{array}{l}\text { Multiple } \\
\text { Investors }\end{array}$ & $\begin{array}{c}\text { Single } \\
\text { Investors }\end{array}$ & All Plants \\
\hline \multicolumn{2}{|l|}{ Number of plants } & 98 & 167 & 265 \\
\hline \multicolumn{2}{|c|}{ Plant characteristics: } & $(\%)$ & $(\%)$ & $(\%)$ \\
\hline \multirow[t]{3}{*}{ Plant type: } & Start-up & 65.3 & 59.9 & 61.9 \\
\hline & Acquisition & 26.5 & 31.7 & 29.8 \\
\hline & 「Joint venture & 8.2 & 8.4 & 8.3 \\
\hline \multicolumn{2}{|l|}{ Urban location } & 55.1 & 71.3 & 65.3 \\
\hline \multirow[t]{4}{*}{ Activity: } & Chemicals & 11.2 & 7.2 & 8.7 \\
\hline & Machinery and equipment & 7.1 & 7.2 & 7.2 \\
\hline & Communications & 14.3 & 5.4 & 8.7 \\
\hline & Transport equipment & 15.3 & 5.4 & 9.1 \\
\hline \multicolumn{2}{|l|}{ All manufacturing } & 82.7 & 57.5 & 66.8 \\
\hline \multicolumn{2}{|l|}{ Grant } & 38.8 & 19.8 & 26.8 \\
\hline \multirow[t]{4}{*}{ Country of origin: } & North America & 30.6 & 40.1 & 36.6 \\
\hline & Western Europe & 34.7 & 35.9 & 35.5 \\
\hline & Far East & 34.7 & 19.2 & 24.9 \\
\hline & Rest of the World & 0.0 & 4.8 & 3.0 \\
\hline \multirow{2}{*}{\multicolumn{2}{|c|}{ Plant survival }} & 88.8 & 76.6 & 81.1 \\
\hline & & (mean) & (mean) & (mean) \\
\hline \multicolumn{2}{|c|}{ Initial plant size (mean number of jobs) } & 168 & 140 & 150 \\
\hline \multicolumn{2}{|c|}{ Initial investment (mean year) } & 1989 & 1993 & 1992 \\
\hline
\end{tabular}

Note: Characteristics refer to date of initial investment. Variables are described in Appendix 2. Plant age is zero for start-up plants and omitted. 
$\underline{\text { Table 4: Empirical Hazard Rates for First Re-investment }}$

\begin{tabular}{ccccccc}
\hline $\begin{array}{c}\text { Duration } \\
\text { (years) }\end{array}$ & \multicolumn{2}{c}{ All plants } & \multicolumn{2}{c}{ Start-ups } & \multicolumn{2}{c}{ Acquisitions } \\
& $h\left(\Delta t_{i}\right)$ & no. & $h\left(\Delta t_{i}\right)$ & no. & $h\left(\Delta t_{i}\right)$ & no. \\
\hline & & & & & & \\
1 & 7.81 & $(191)$ & 6.19 & $(113)$ & 12.90 & $(61)$ \\
2 & 9.76 & $(164)$ & 10.00 & $(100)$ & 10.64 & $(47)$ \\
3 & 9.60 & $(125)$ & 8.86 & $(79)$ & 6.06 & $(33)$ \\
4 & 7.77 & $(103)$ & 9.23 & $(65)$ & 3.45 & $(29)$ \\
5 & 7.32 & $(82)$ & 7.69 & $(52)$ & 4.55 & $(22)$ \\
6 & 7.58 & $(66)$ & 9.30 & $(43)$ & 0 & $(17)$ \\
7 & 8.93 & $(56)$ & 8.11 & $(37)$ & 7.14 & $(14)$ \\
8 & 2.44 & $(41)$ & 3.33 & $(30)$ & 0 & $(7)$ \\
9 & 0 & $(33)$ & 0 & $(26)$ & 0 & $(4)$ \\
10 & 9.52 & $(21)$ & 5.88 & $(17)$ & 50.00 & $(2)$ \\
11 & 7.69 & $(13)$ & 9.09 & $(11)$ & - & $(0)$ \\
12 & 0 & $(7)$ & 0 & $(5)$ & - & $(0)$ \\
13 & 0 & $(6)$ & 0 & $(4)$ & 0 & $(1)$ \\
\hline
\end{tabular}

Note: Figures in parentheses are number of observations on which each calculation is based. Surviving plants only $(S U R V I V E=1)$. 
Table 5: Median Re-investment Durations by Initial Plant Size: Years

\begin{tabular}{lccccc}
\hline Initial plant employment size & 10 & 50 & 100 & 250 & 500 \\
\hline & & & & & \\
All plants & 12.1 & 9.4 & 7.1 & 4.1 & 3.8 \\
Start-up plants & 11.1 & 8.8 & 6.7 & 3.6 & 2.4 \\
Acquisition plants & 15.1 & 12.7 & 8.9 & 5.4 & 6.2 \\
\hline
\end{tabular}

Note: Re-estimation of equations in Appendix 3 with all covariates omitted except the country of origin (coefficients restricted to be the same), constant and quadratic employment size terms. 
Table 6: Probit Results for Re-investment

\begin{tabular}{lccc}
\hline Dependent variable: MULTIPLE & All plants & Start-ups & Acquisitions \\
\hline Urban & - & - & $-1.749 * * *$ \\
Multi-plant firm & $0.694^{* *}$ & $1.254^{* * *}$ & - \\
Plant relocation & $0.839^{*}$ & - & - \\
Grant & - & $0.875^{* * *}$ & - \\
Communications activity & - & $0.885^{* *}$ & - \\
Non-manufacturing & $-1.000^{* * *}$ & - & - \\
North America origin & $6.088^{* * *}$ & $6.637^{* * *}$ & - \\
Western Europe origin & $5.961 * * *$ & $6.588^{* * *}$ & - \\
Far East origin & $6.511^{* * *}$ & $6.959^{* * *}$ & - \\
Constant term & $-13.027 * * *$ & $-8.591 * * *$ & 0.421 \\
\hline $\mathrm{n}$ & 242 & 147 & 75 \\
LogL & -100.8 & -107.3 & -32.5 \\
\hline
\end{tabular}

Note: Parsimonious results. Variables in part (a) of the Appendix 2 are included but deleted sequentially according to least significant. Fixed effects are included in each case but not shown for the time duration over which a plant is observed, i.e., $1998-Y E A R_{I} . * * *=$ significant at $1, * *=5$ and $*=10 \%$ level. 
Table 7: Survival Results With and Without Selection Terms

\begin{tabular}{|c|c|c|c|c|c|c|}
\hline \multirow[b]{2}{*}{ Start-up plants } & \multicolumn{2}{|c|}{ All plants } & \multicolumn{2}{|c|}{ Start-ups } & \multicolumn{2}{|c|}{ Acquisitions } \\
\hline & -0.085 & -0.048 & - & - & - & - \\
\hline Acquisition plants & -0.193 & -0.188 & - & - & - & - \\
\hline Plant employment size $\left(\mathrm{x} 10^{-3}\right)$ & -0.096 & -0.103 & $-0.302 * * *$ & $-0.292 * *$ & 0.979 & $1.411 * * *$ \\
\hline Plant age & 0.002 & 0.001 & - & - & $0.009 * *$ & $0.005^{*}$ \\
\hline Urban location & -0.034 & -0.009 & -0.021 & -0.024 & - & - \\
\hline Multi-plant firm & - & - & - & - & $3.349 * * *$ & $3.870 * * *$ \\
\hline Plants at same site & $3.919 * * *$ & $4.473 * * *$ & $3.330 * * *$ & $3.388 * * *$ & - & - \\
\hline Plant relocation & - & - & -0.192 & -0.185 & -0.489 & 0.294 \\
\hline Grant & 0.048 & 0.026 & - & - & -0.076 & $0.664 * * *$ \\
\hline Chemicals activity & -0.042 & -0.088 & 0.130 & 0.117 & 0.752 & -0.328 \\
\hline Machinery activity & $0.381 *$ & 0.310 & $0.403 *$ & 0.381 & $4.793 * * *$ & $3.292 * * *$ \\
\hline Communications activity & $-0.477 * *$ & $-0.526 * * *$ & - & - & -0.024 & -0.326 \\
\hline Transport activity & -0.376 & -0.358 & -0.209 & -0.206 & -2.175 & $-2.914 * * *$ \\
\hline Non-manufacturing & - & - & -0.218 & -0.220 & 1.917 & 1.499 \\
\hline Minimum efficient scale & $0.422 * * *$ & $0.339 * * *$ & 0.181 & 0.182 & $1.846^{*}$ & $1.391^{*}$ \\
\hline Market concentration & $1.516^{*}$ & $1.432 *$ & $1.090 *$ & 1.045 & $12.938 *$ & $14.231 * * *$ \\
\hline Industry growth rate & 0.022 & 0.024 & $0.032 *$ & $0.032 *$ & $0.112 * *$ & $0.074 * *$ \\
\hline Regional growth rate & $0.041^{*}$ & $0.039 *$ & 0.041 & 0.041 & -0.093 & -0.074 \\
\hline Exchange rate & $-0.044 * * *$ & $-0.043 * *$ & $-0.042 * *$ & $-0.043 * *$ & 0.043 & -0.057 \\
\hline North America origin & - & - & - & - & $-2.529 * * *$ & $-1.001 * * *$ \\
\hline Western Europe origin & - & - & - & - & $-2.441 * * *$ & $-1.040^{*}$ \\
\hline Far East origin & - & - & - & - & 0.980 & $2.278 * * *$ \\
\hline Constant & 0.758 & $1.050 * *$ & $1.611 * * *$ & $1.609 * * *$ & -3.436 & -2.831 \\
\hline Multiple Investor (MULTIPLE) & $0.403 * * *$ & 1.674 & $0.293 * * *$ & 0.248 & 0.149 & -0.416 \\
\hline Multiple selection $\left(\hat{\lambda}_{m}\right)$ & - & -0.179 & - & 0.052 & - & -0.361 \\
\hline Single selection $\left(\hat{\lambda}_{s}\right)$ & - & 0.001 & - & -0.001 & - & $-1.066 * * *$ \\
\hline Shape parameter $(\kappa)$ & $4.194 * * *$ & $4.233 * * *$ & $4.875 * * *$ & $4.880 * * *$ & $5.839 * * *$ & $7.421 * * *$ \\
\hline $\mathrm{n}$ & 242 & 242 & 147 & 147 & 75 & 75 \\
\hline $\log L$ & -71.1 & -69.8 & -43.0 & -42.9 & -10.0 & -6.8 \\
\hline Pseudo $\mathrm{R}^{2}$ & 0.28 & 0.29 & 0.33 & 0.33 & 0.65 & 0.76 \\
\hline
\end{tabular}

Note: ML estimation of (1) with (2a) with time origin equal to the year of initial investment $\left(Y E A R_{I}\right)$. Selection terms in (A4) of Appendix 1 are included in the second regression in each case, based on the respective probits in Table 6 . Terms in Table 6 are omitted to identify selection terms, but are insignificant (see text). Variables given in Appendix 2. Plant age is zero for start-ups and plants at same site is zero for acquisitions, and omitted. Robust standard errors. $* * *=$ significant at the $1, * *=5$ and $*=10 \%$ level. 


\section{$\underline{\text { References }}$}

Andersson, U., Forsgren, M and Holm, U. (2002), The Strategic Impact of External Networks: Subsidiary Performance and Competence Development in the Multinational Corporation, Strategic Management Journal, 23, 979-96.

Audretsch, D. and Mahmood, M. (1994), The Rate of Hazard Confronting New Firms and Plants in US Manufacturing, Review of Industrial Organisation, 9, 41-56.

Baden-Fuller, C. (1989) Exit from Declining Industries and the Case of Steel Castings, Economic Journal, 99, 949-69.

Barba-Navaretti, G. and Venables, A. J. (2004), Multinational Firms in the World Economy, Princeton University Press, New Jersey.

Belderbos, R., Capannelli, G. and Fukao, K. (2001), Backward Vertical Linkages of Foreign Manufacturing Affiliates: Evidence from Japanese Multinationals, World Development, 29, 189-208.

Brand, S., Hill, S. and Munday, M. (2000), Assessing the Impacts of Foreign Manufacturing on Regional Economies: The Cases of Wales, Scotland and the West Midlands, Regional Studies, 34, 343-55.

Colombo, M. G. and Delamstro, M. (2000), A Note on the Relation between Size, Ownership Status and Plant Closure: Sunk Cost versus Strategic Size Liability, Economics Letters, 69, $421-7$.

Cooper, R., Haltiwanger, J. and Power, L. (1999), Machine Replacement and the Business Cycle: Lumps and Bumps, American Economic Review, 89, 921-46.

Coppola, L. (2004), Education and Union Formation as Simultaneous Processes in Italy and Spain, European Journal of Population, 20, 219-50.

Coughlin, C. and Segev, E. (2000), Location Determinants of New Foreign-Owned Manufacturing Plants, Journal of Regional Science, 40, 323-52.

Coughlin, C., Terza, J. and Arromdee, V. (1991), State Characteristics and the Location of FDI within the United States, Review of Economics and Statistics, 73, 675-83.

Cressy, R. (1996). Are Business Start-ups Debt-Rationed?, Economic Journal, 106, 153-70.

Criscuolo, P., Narula, R. and Verspagen, B. (2002), The Relative Importance of Home and Host Innovation Systems in the Internationalisation of MNE R\&D: A Patent Citation Analysis, Centre for Innovation Studies, Eindhoven.

Criscuolo, P. and Salter, A. (2006), Easy Come Easy Go: Embeddedness and Survival of Foreign Subsidiaries in the UK, Report to Department of Trade and Industry, London. 
Crozet, M., Mayer, T. and Mucchielli, J-L. (2004), How Do Firms Agglomerate? A Study of FDI in France, Regional Science and Urban Economics, 34, 27-54.

Culem, G. G. (1988), The Locational Determinants of Direct Investments Among Industrialised Countries, European Economic Review, 32, 885-904.

Devereux, M. P., Griffith, R. and Simpson, H. (2007), Firm Location Decisions, Regional Grants and Agglomeration, Journal of Public Economics, 91, 413-35.

Dunne, P. and Hughes, A. (1994), Age, Size, Growth and Survival: UK Companies in the 1980s, Journal of Industrial Economics, 62, 115-40.

Dunne, T., Roberts, M. and Samuelson, L. (1988), Patterns of Firm Entry and Exit in US Manufacturing Industries, RAND Journal of Economics, 19, 495-515.

Ernst and Young (2004), European Investment Monitor, Ernst and Young, London.

Fabbri, F. Haskel, J. and Slaughter, M. (2002), Globalisation and Labour Demand Elasticities in Britain, Paper presented at the Adjusting to Globalisation Conference, University of Nottingham, June.

Fothergill, S. and Guy, N. (1990, Retreat from the Regions: Corporate Change and the Closure of Factories, Regional Studies Association, London.

Friedman, J., Gerlowski, D. and Silberman, J. (1992), What Attracts Foreign Multinational Corporations? Evidence from Branch Plant Location in the United States, Journal of Regional Science, 32, 403-18.

Froot, K. A. and Stein, J. C. (1991), Exchange Rates and Foreign Direct Investment: An Imperfect Capital Markets Approach, Quarterly Journal of Economics, 1191-1217.

Gabe, T. M. and Kraybill, D. S. (2002), The Effect of State Economic Development Incentives on Employment Growth of Establishments, Journal of Regional Science, 42, 703-30.

Girma, S. and Görg, H. (2003), Blessing or Curse? Domestic Plants' Survival and Employment Prospects after Foreign Acquisition, IZA Discussion Paper No. 706, Bonn.

Görg, H. and Strobl, E. (2002), "Multinational Companies and Indigenous Development: An Empirical Analysis”, European Economic Review, 46, 1305-22.

Görg, H. and Strobl, E. (2003), "Footloose Multinationals”, Manchester School, 71, 1-19.

Greene, W. H. (2003), Econometric Analysis, fifth edition, Prentice Hall, New Jersey.

Griffith, R. (1999), Using the ARD Establishment Level Data to Look at Foreign Ownership and Productivity in the United Kingdom, Economic Journal, F416-41.

Guimaraes, P., Figueiredo, O. and Woodward, D. (2000), Agglomeration and the Location of Foreign Direct Investment in Portugal, Journal of Urban Economics, 47, 115-35. 
Haltiwanger, J. C. and Schuh, S. (1999), Gross Job Flows between Plants and Industries, New England Economic Review, March / April.

Harris, R. I. D. and Hassaszadeh, P. (2002), The Impact of Ownership Changes and Age Effects on Plant Exits in UK Manufacturing, 1974-95, Economics Letters, 75, 309-17.

Harris, R. I. D. and Robinson, C. (2005) The Impact of Regional Selective Assistance on Sources of Productivity Growth: Plant Level Evidence from UK Manufacturing 1990-1998, Regional Studies, 39, 751-765.

Head, K., Ries, J. and Swenson, D. (1995), Agglomeration Benefits and Location Choice: Evidence from Japanese Manufacturing Investments in the United States, Journal of International Economics, 38, 223-47.

Head, K., Ries, J. and Swenson, D. (1999), Attracting Foreign Manufacturing: Investment Promotion and Agglomeration, Regional Science and Urban Economics, 29, 197-218.

Jones, J. and Wren, C. (2004), Do Inward Investors Achieve their Job Targets?, Oxford Bulletin of Economics and Statistics, 66, 483-513.

Jones, J. and Wren, C. (2006), Foreign Direct Investment and the Regional Economy, Ashgate, Aldershot.

Jones, J. and Wren, C. (2008a), 'Inward Investment Policy and FDI Location across British Regions', European Regional Science Association conference, August.

Jones, J. and Wren, C. (2008b), 'Foreign Inward Investment and Regional Economic Prospects', Northern Economic Review, 38, 61-79.

Kim, S.-H., Pickton, T. and Gerking, S. (2003), Foreign Direct Investment: Agglomeration Economies and Returns to Promotion Expenditures, Review of Regional Studies, 33, 61-72.

Lawless, J. F. (1982), Statistical Models and Methods for Lifetime Data, John Wiley, New York.

Lee, L. F. (1976), Estimation of Limited Dependent Variable Models by Two-Stage Methods, PhD dissertation, Department of Economics, University of Rochester.

Lillard, L. A. (1993), Simultaneous Equations for Hazards, Journal of Econometrics, 56, 189217.

Maddala, G. S. (1983), Limited-Dependent and Qualitative Variables in Econometrics, Cambridge University Press, Cambridge, UK.

Mata, J., Portugal, P. and Guimaraes, P. (1995), The Survival of New Plants: Start-up Conditions and Post-entry, International Journal of Industrial Organisation, 13, 459-81. 
McCloughan, P. and Stone, I. (1998), Life Duration of Foreign Multinational Subsidiaries: Evidence from UK Northern Manufacturing Industry, 1970-93, International Journal of Industrial Organisation, 16, 719-47.

Nilsen, Ø. A. and Schiantarelli, F. (2003), Zeros and Lumps in Investment: Empirical Evidence on Irreversibilities and Nonconvexities, Review of Economics and Statistics, 85, 1021-37.

Phelps, N., MacKinnon, D., Stone, I. and Braidford, P. (2003), Embedding the Multinationals? Institutions and the Development of Overseas Manufacturing Affiliates in Wales and North East England, Regional Studies, 37, 27-40.

Stone, I., Hunt, A. and Holmes, P. R. (2008), An Analysis of New Firm Survival using a Hazard Function, Applied Economics, forthcoming.

UNCTAD (2004), Prospects for Foreign Direct Investment and the Strategies of Transnational Corporations, 2004-2007, United Nations Conference on Trade and Development, United Nations, New York.

Watts H. and Kirkham, J. (1999), Plant Closures by Multi-Locational Firms: A Comparative Perspective, Regional Studies, 33, 413-24.

Wren, C. (2005), Regional Grants: Are They Worth It?, Fiscal Studies, 26, 245-75.

Young, S., Hood, N. and Peters, E. (1994), Multinational Enterprises and Regional Economic Development, Regional Studies, 28, 756-77. 


\section{Appendix 1: Selection and Unobserved Effects}

(a) Selection on Observables

In the abstract, the problem is written as a pair of linear equations:

$$
\begin{array}{ll}
\text { Multiple Investor }(m): & y_{i m}=x_{i m} \beta_{\boldsymbol{l m}}+\beta_{2 m} \operatorname{MULTIPLE}_{i}+u_{i m} \\
\text { Single Investor }(\mathrm{s}): & y_{i s}=\boldsymbol{x}_{i s} \beta_{\boldsymbol{l s}}+u_{i s}
\end{array}
$$

A continuous latent variable $I_{i}{ }^{*}$, is defined, which indicates the propensity to re-invest, where $z_{i}$ is a vector of characteristics determining the re-investment probability, with coefficients $\gamma$, and $u_{i}$ is an error term, as follows:

$$
\text { Selector equation: } \quad I_{i}^{*}=z_{i} \gamma+u_{i}
$$

The observed outcome $y_{i}$ is defined by $y_{i}=y_{i m} \Leftrightarrow I_{i}^{*}>0$ and $y_{i}=y_{i s} \Leftrightarrow I_{i} * \leq 0$. Formally, selection bias arises when the stochastic element of the selector equation is correlated with the stochastic elements of equations (A1) and (A2), leading to inconsistent estimates of $\beta$. The twostage procedure is as follows. First, (A3) is estimated as a probit model with observations on the indicator variable $I_{i}\left(I_{i}=1 \Leftrightarrow I_{i}^{*}>0\right.$ and $\left.I_{i}=0 \Leftrightarrow I_{i}^{*} \leq 0\right)$, giving $\hat{\gamma}$. Second, it is used to jointly estimate (A1) and (A2), but with an additional regressor in each case as:

$$
\lambda_{i m}=\phi\left(\hat{\gamma} z_{i}\right) / \Phi\left(\hat{\gamma} z_{i}\right) \text { and } \lambda_{i s}=\phi\left(\hat{\gamma} z_{i}\right) /\left[1-\Phi\left(\hat{\gamma} z_{i}\right)\right]
$$

where $\phi$ and $\Phi$ are the normal density and distribution functions. This supposes that the error terms of (A1), (A2) and (A3) are jointly normal, so that letting $\sigma_{m}$ and $\sigma_{s}$ denote the covariances between $u_{m i}, u_{s i}$ and $u_{i}$ respectively, the conditional expectations of the error terms in (A1) and

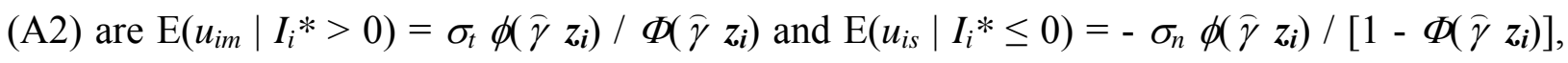
which is the basis for the inverse Mills ratio selection terms in (A4).

\section{(b) Unobserved Effects}

Lillard (1993) jointly estimates a pair of simultaneous equations in which the endogenous terms are measured as log hazards. This is basically a model of proportional hazards, since writing the 
proportional hazards model as $h(\Delta t)=\mu h_{o}(\Delta t)$, and parameterising this by setting $\mu \equiv \exp (-\boldsymbol{x} \beta)$ gives $\ln h(\Delta t)=-\boldsymbol{x} \beta+\alpha$ in log-linear form, where $h_{o}$ is the baseline function (i.e. $\boldsymbol{x}=0$ ).

In our case it is possible to determine empirical hazard rates for survival, but the actual time durations are not observed (only whether the plant survived to the year 2000), which means we are unable to estimate equations in log hazards. The corresponding survivor function is $S(\Delta t)$ $=\left[S_{o}(\Delta t)\right]^{\mu}$, and under the same parameterization this gives $\ln [-\ln S(\Delta t)]=-\boldsymbol{x} \beta+\alpha$. It means we regress the following equations, which maintains the property of proportional hazards:

$$
\begin{aligned}
& \text { Survival: } \ln \left[-\ln S^{S}(\Delta t)\right]=\alpha^{S}+\boldsymbol{x} \beta^{S}+\beta_{m} M U L T I P L E+\delta_{m} \hat{\lambda}_{m}+\delta_{s} \hat{\lambda}_{s}+\varepsilon^{S} \\
& \text { Re-investment: } \quad \ln \left[-\ln S^{R}(\Delta t)\right]=\alpha^{R}+\boldsymbol{x} \beta^{R}+\varepsilon^{R}
\end{aligned}
$$

The $\varepsilon^{S}$ and $\varepsilon^{R}$ terms capture the unobserved heterogeneity. It is assumed that these are normally distributed with zero mean and variances of $\sigma_{S}^{2}$ and $\sigma_{R}^{2}$ respectively. The co-variances are timeinvariant of the form $\sigma_{S R}=\rho \sigma_{S} \sigma_{R}$, all of which are standard assumptions (see Lillard, 1993, and numerous applications in the labor-related literature, e.g., Coppola, 2004). It is advantageous as the selection terms in (A5) are formed under the assumption of joint normality. The inclusion of the selection terms for observables means MULTIPLE can be treated as exogenous, so (A5) and (A6) are jointly estimated according to the method of Zellner. ${ }^{17}$

For plants commencing in foreign ownership in each year we calculate the survival rate, and regress (A5) and (A6) across 242 plants. The covariate should not be identical. In the case of (A5) we use the covariates for all plants in Table 7, while for (A6) we pare these down to get the parsimonious form, which is like before. 


\section{Appendix 2: The Variables}

Variable description and measurement (zero values give base case)

(a) Plant, industry and regional characteristics:

Plant type - mode of entry: $1=$ Start-up, 2 = Acquisition (or merger), $0=$ Joint venture.

Plant employment size - initial project job scale: total number of employees. ${ }^{b}$

Plant age - from initial establishment to initial investment: years.

Urban location: $1=$ metropolitan counties of Tyne and Wear and Cleveland and $0=$ elsewhere.

Multi-plant firm - other plants in region with same owner: $=1$, otherwise zero.

Plants at same site - other plants, possibly related: $=1$, otherwise zero.

Plant relocation - since $1985:=1$, otherwise zero.

Grant - receipt of Regional Selective Assistance grant in initial project: $=1$, otherwise zero.

Manufacturing activity -2-digit industry level: $1=$ Chemicals, $2=$ Machinery and equipment, 3

$=$ Communications, $4=$ Transport equipment and $0=$ Rest of industry. $^{\mathrm{c}}$

Non-manufacturing sectors: $1=$ non-manufacturing, $0=$ manufacturing.

Minimum efficient scale - 2-digit industry level: log of median employment size.

Market concentration - Herfindahl index at 2-digit industry level using employment.

Industry growth rate - annual 2-digit UK net employment growth rate over 1985-2000: \%.

Regional growth rate - annual GDP growth rate in host region for year of initial investment: \%. ${ }^{\mathrm{d}}$

Exchange rate - annualised 5-year sterling exchange rate with source country after $Y E A R_{I}: \%^{\mathrm{d}}$

Country of origin - supranational region of ultimate owner: $1=$ North America, $2=$ Western

Europe, $3=$ the Far East and $0=$ Rest of the World.

(b) Investment, survival and temporal variables

Multiple Investor (MULTIPLE) - plants implementing more than one project over 1985-98: $1=$ Multiple Investor, $0=$ Single Investor.

Plant survival (SURVIVE) - plant survival at the year 2000: $1=$ survivor, $0=$ non-survivor.

Year of the initial investment $\left(Y E A R_{I}\right): 1985,1986, \ldots, 1998$.

Year of first re-investment $\left(Y E A R_{R}\right): 1986,1987, \ldots, 1998 .^{\mathrm{e}}$

Time duration between initial and first re-investment $\left(D U R_{R} \equiv Y E A R_{R}-Y E A R_{I}\right)$ : years. ${ }^{\mathrm{e}}$

Time duration between initial investment and year $2000\left(D U R_{2000} \equiv 2000-Y E A R_{I}\right)$ : years.

Note:

a. Plant characteristics measured at time of initial investment.

b. Plant size is not known in 23 cases.

c. The activity is defined by the NACE classification (see text).

d. Source: Economic Trends and Regional Trends; otherwise from authors' own database.

e. These variables defined only if MULTIPLE $=1$. 


\section{Appendix 3: Results for Re-investment Duration: Surviving Plants}

\begin{tabular}{|c|c|c|c|}
\hline Dependent variable: $D U R_{R}$ & All plants & Start-ups & Acquisitions \\
\hline Start-up plants & -0.169 & - & - \\
\hline Acquisition plants & -0.628 & - & - \\
\hline Plant employment size (x 10 $\left.0^{-3}\right)$ & $-6.065 * * *$ & $-6.637 * * *$ & -6.348 \\
\hline Plant employment size: squared $\left(\times 10^{-6}\right)$ & $8.420^{*}$ & $7.250 *$ & 8.240 \\
\hline Plant age & 0.010 & - & 0.009 \\
\hline Urban location & $0.372 *$ & 0.253 & $1.658 * * *$ \\
\hline Multi-plant firm & -0.177 & $-0.808 * *$ & 0.209 \\
\hline Plants at same site & 0.625 & -0.050 & - \\
\hline Plant relocation & -0.297 & -0.119 & -0.721 \\
\hline Grant & -0.186 & -0.433 & 1.047 \\
\hline Chemicals activity & -0.553 & -0.431 & -1.523 \\
\hline Machinery activity & -0.327 & -0.274 & -2.009 \\
\hline Communications activity & -0.150 & -0.428 & -0.239 \\
\hline Transport activity & 0.223 & 0.406 & $3.862 *$ \\
\hline Non-manufacturing & 0.318 & -0.399 & $4.127 * *$ \\
\hline Minimum efficient scale & -0.243 & -0.296 & -0.087 \\
\hline Market concentration & -3.374 & -1.312 & $19.720 * *$ \\
\hline Industry growth rate & -0.043 & 0.014 & -0.310 \\
\hline Regional growth rate & $-0.130 *$ & -0.071 & $-0.317^{*}$ \\
\hline Exchange rate & 0.043 & 0.020 & 0.047 \\
\hline North America origin & $-8.681 * * *$ & $-7.978 * * *$ & $-12.969 * *$ \\
\hline Western Europe origin & $-9.920 * * *$ & $-8.522 * * *$ & $-12.647 * *$ \\
\hline Far East origin & $-9.323 * * *$ & $-8.551 * * *$ & $-13.322 * *$ \\
\hline Constant & $13.092 * * *$ & $12.671 * * *$ & 15.783 \\
\hline Shape parameter $(\kappa)$ & $1.776 * * *$ & $2.118 * * *$ & $1.879 * * *$ \\
\hline $\mathrm{n}$ & 191 & 113 & 61 \\
\hline $\log L$ & -141.58 & -77.03 & -36.05 \\
\hline Pseudo $\mathrm{R}^{2}$ & 0.19 & 0.27 & 0.31 \\
\hline
\end{tabular}

Note: ML estimation of (3) with (2). Plant age is zero for start-ups and plants at same site is zero for acquisitions. Robust standard errors. $* * *=$ significant at $1, * *=5$ and $*=10 \%$ level. 


\section{$\underline{\text { Notes }}$}

${ }^{1}$ Not conditioning on the plant characteristics, such as size and industry, Görg and Strobl (2003) and Fabbri et al (2002) find that the survival durations are actually longer for foreign-owned plants. Explanations of a higher conditional failure rate for FDI plants stem from their multiplant nature, with parent companies closing plants to avoid fixed costs (Baden-Fuller, 1989), or remoteness from a parent making exit more likely (Watts and Kirkham, 1999). There are other explanations for greater employment volatility (see Barba-Navaretti and Venables, 2004).

${ }^{2}$ It is given impetus by the enlargement of the European Union, which made locations in Eastern Europe more attractive (UNCTAD, 2004), such that internal cross-border FDI is now the major component of FDI in the European Union (Ernst and Young, 2004).

${ }^{3}$ Supposing that the re-investment serves to "embed" plants then the effect of missing data on re-investment would be to bias downwards the estimate of this effect.

${ }^{4}$ A project is a discrete investment that the investor plans to have in place over the short run, usually within two years of formal commitment. Commitments in different years are treated as distinct projects. Plants implementing an initial investment prior to 1985 are not included.

${ }^{5}$ The data were checked and cleaned. Projects were assigned to plants by name, location and activity, and using numerous corroborating sources, including computerized and other business directories, contact with the investors and with firms in related activities, and interviews with regional and local agencies. Jones and Wren (2006) give full details on this.

${ }^{6}$ An acquisition is where a foreign firm has more than a 50 per cent stake in a UK-owned company, and a joint venture is where there is at least a 50 per cent stake in a venture.

${ }^{7}$ An analysis of job projections in Jones and Wren (2004) suggests that targets were if anything under-achieved, but this is the opposite of what is expected if there are missing data.

${ }^{8}$ RSA data were collected from published sources, with central government supplying smaller unpublished cases. Only 13 grant cases could not be matched, which is 2 per cent by value. For studies using census data, where the plant name is not disclosed, the matching is made on such things as location and industry, and is only around fifty per cent, e.g. Devereux et al (2007).

${ }^{9}$ The time duration at which the hazard rate is at a maximum is found by differentiating (2b) with respect to $\Delta t$ to get $\Delta t^{\max }=(\kappa-1)^{1 / \kappa} \exp \left(\boldsymbol{x}_{\boldsymbol{i}} \beta\right)$, where $\exp \left(\boldsymbol{x}_{\boldsymbol{i}} \beta\right)$ is the median duration. Evaluating $(\kappa-1)^{1 / \kappa}$ using the estimates of $\kappa$ in Table 7 below gives a value of about 1.33.

${ }^{10}$ Thirty-eight percent re-invest and $84 \%$ survive, which is almost identical to that for all plants, at $37 \%$ and $81 \%$, shown in Table 1 . In order to maximise the sample size we do not reduce the overall sample to 242 observations, but work with 265 observations where feasible. 
${ }^{11}$ The 2-digit industries are chemicals (NACE code 24); machinery and equipment, including domestic electrical appliances (29); radio, television and communications equipment, including electronic components (32); and transport equipment, including motor vehicles (34).

${ }^{12}$ In non-conditional form and dropping $i$ subscripts, the $\log$-likelihood function is $\log L=\Sigma_{i}[\delta$ $\log f(\Delta t)+(1-\delta) \log S(\Delta t)]$, where $f(\Delta t)$ is the probability density function of the actual reinvestment durations, $\Delta t$. The hazard $h(\Delta t)$ is the probability that a firm becomes a Multiple Investor $f(\Delta t)$ given that it has not already re-invested $S(\Delta t)$, i.e. $f(\Delta t) \equiv h(\Delta t) S(\Delta t)$. Putting this in the above expression gives (3). It handles the data-censoring problem in re-investment, as $\delta=$ 1 if there is an observation on $h(\Delta t)$, but $\delta=0$ if the plant gets to 1998 as a Single Investor, in which case there is an observation on $S(\Delta t)$.

${ }^{13}$ The Weibull distribution implies a monotonic hazard rate, but linearity is also rejected by the data by regressing a 'log-log plot' with a quadratic term (see Lawless, 1982).

${ }^{14}$ Even though the selection terms are insignificant in Table 7 the convention is to leave these terms in the regression equations in order that capture the selection effect.

${ }^{15}$ If it is possible to fully control for selection, based on observables and non-observables, then the Multiple Investors will be a random draw from the population of foreign-owned plants, and we will have successfully addressed the endogeneity issue.

${ }^{16}$ In fact, when the equation is re-estimated with the time origin taken as the year of the initial investment $\left(Y E A R_{I}\right)$ for Single Investors and the year of the re-investment $\left(Y E A R_{R}\right)$ for Multiple Investors the MULTIPLE term is insignificant, supporting this contention.

${ }^{17}$ Lillard (1993) estimates a pair of simultaneous equations in log hazards, where one equation includes the log hazard from the other equation as a covariate. Like here, in some applications this covariate is measured in a binary form (e.g., Coppola, 2004). 


\section{BERR}

\section{Spatial Economics Research Centre (SERC)}

London School of Economics

Houghton Street

London WC2A 2AE

Tel: 02078523565

Fax: 02079556848

Web: www.spatialeconomics.ac.uk

SERC is an independent research centre funded by the Economic and Social Research Council (ESRC), Department for Business, Enterprise and Regulatory Reform (BERR), the Department for Communities and Local Government (CLG) and the Welsh Assembly Government. 